\title{
Preliminaries: A Note to Readers
}

A Dictionary of Sociolinguistics is intended as a useful resource for students, teachers and researchers in sociolinguistics, or any area of language study that takes a socially-oriented approach (e.g. communication studies, language and gender, language and power, critical discourse analysis). The dictionary is also relevant to the study of related areas that sometimes focus on language, texts or discourse, such as anthropology, psychology and sociology. We hope that, in addition, it will interest people with an 'applied' interest in language, such as educationists and policy-makers.

Sociolinguistics is an exciting and academically vibrant area, marked by increasing diversity. A glance through the programme of any contemporary conference in the subject will reveal a wide range of topics and analytical approaches, informed by divergent, and sometimes conflicting, paradigms and perspectives. This is reflected in dictionary entries, where velar rubs shoulders with ventriloquation, post-vocalic $|r|$ with poststructuralism and substrate with subjectivity. This is not just a matter of discrete research traditions: the same researcher may be engaged with technical linguistic description whilst grappling with contemporary theories about the nature of language, personhood and the self. On a practical level, this means that students of sociolinguistics are faced with a proliferation of terms and concepts - sometimes a minefield, with the same term used to different effect or different terms used to characterise broadly similar phenomena within different fields of enquiry. In explaining sociolinguistic terminology, the dictionary will also map out the traditions and approaches that comprise sociolinguistics and thus help to locate and contextualise terms and concepts.

\section{Academic Coverage}

The dictionary covers contemporary sociolinguistics as this has developed since the 1960s. It also covers some earlier work in areas such as 
dialectology and anthropological linguistics/linguistic anthropology that are relevant to contemporary sociolinguistics. In terms of contemporary approaches, the dictionary adopts a broad coverage. It includes various approaches to the study of language variation and change; language contact phenomena, including bilingual language use; language in interaction; the socially oriented analysis of text and discourse; critical language study; specific topics such as language and gender, literacy, intercultural communication and international/global languages; applied areas such as language policy and planning, and language in education.

Where appropriate, entries indicate changes and differences in the use of terms, and locate these within particular traditions of enquiry. Entries try to provide an 'insider' perspective whilst also adopting a broadly critical approach to the discussion of linguistic ideas and concepts: an overall aim of the dictionary is to support critical engagement and dialogue with the discipline.

The dictionary includes technical terms that we think have some currency in sociolinguistics, and that readers are likely to encounter in academic texts. It does not include terms that are highly specific (i.e. that have limited currency) or that seem unlikely to 'bed down' within the discipline. Nor does it include terms that are also found with the same meanings in everyday language use (e.g. alphabet). But it does include terms that are given a particular inflection within sociolinguistics, or that are used differently from their more everyday sense (e.g. accent, dialect, style). We have paid particular attention to terms that are used differently within different traditions (e.g. discourse, text, voice).

We include a small number of names of people who might be regarded as foundational within sociolinguistics (e.g. Labov, Hymes) or whose theories are increasingly being drawn on in sociolinguistic study (e.g. Bakhtin, Foucault). These are restricted to people who have more or less 'adjectival' status within the discipline, and who might be referred to in sociolinguistic texts with limited explanation, on the assumption that their main ideas are known. Because of the way this (and other) academic disciplines have developed, the names include a preponderance of white Anglophone (or European) male academics: a situation likely to change over the next few years. For a fuller list of key sociolinguistic figures, see Rajend Mesthrie's (2001) Concise Encyclopaedia of Sociolinguistics.

We faced a problem in deciding which terms to include from linguistic description and analysis. Since, in principle, sociolinguists may study any aspect of language, we ran the risk of reproducing other excellent reference works such as David Crystal's (2002) Dictionary of Linguistics 
and Phonetics. We decided eventually not to include terms students of sociolinguistics might be expected to have as part of their general knowledge about language (e.g. noun, verb, adjective); nor have we included more specialist terms unlikely to occur in the sociolinguistics literature (e.g. adjunct). This gives us a bias towards certain types of language description: e.g. common descriptors for sounds, which frequently occur as variables in sociolinguistic analyses of language variation and change; to a lesser extent, some grammatical terms found in variationist research; descriptive terms likely to occur in sociolinguistic analyses of text, discourse or conversation. Crystal probably remains the most comprehensive and concise source for general linguistic terminology.

\section{How entries are organised}

Entries may contain minimal information with a reference to other more relevant entries. However, we have tried to make most entries complete in themselves. This produces occasional overlaps in entries for related terms: we have preferred this to extensive reliance on cross-referencing, which would make individual entries harder to read. Nevertheless, entries do include cross-referencing, which should help readers track related terms and perhaps gain a fuller understanding of a set of concepts. Where relevant, entries include examples; many entries include references to further reading (examples of studies, discussion of a topic etc.) for those who wish to follow up a particular idea. Within entries, we have tried to describe terms in a non-technical way.

On specific conventions adopted in entries, see below. 


\section{Entries adopt the following conventions:}

- bold type is used for terms explained in the entry that have no separate entry of their own;

- SMALl CAPITALs are used for terms explained in separate entries, but we adopt this convention only where it may be useful to cross-refer to such entries;

- italics are used for examples of linguistic items; where these are explained the gloss may be in quotation marks (e.g. lune de miel, meaning 'honeymoon');

- where a term has quite different uses, or where it is helpful to separate out related uses, each definition is separately numbered; however, where uses are closely related we have sometimes found it easier to deal with these together;

- for the representation of speech sounds, we have sometimes used International Phonetic Alphabet symbols. Phonetic symbols are enclosed within square brackets (e.g. [b]); PHONEMES are enclosed within slashes (e.g. /b/); LINGUISTIC VARIABLES used in sociolinguistic studies are enclosed within curved brackets (e.g. (ng) for the final sound in running). We have given examples of speech sounds, usually from English (RP) as a commonly-used reference point likely to be familiar to many readers. The International Phonetic Association web site includes a full set of phonetic symbols: see http://www.arts.gla.ac.uk/IPA/ipachart.html (last accessed October 2003).

- the asterisk * is used as a syntactic convention to mark a sentence or utterance regarded as ungrammatical (i.e. not used in a particular dialect). 